\title{
Patterns of spon 1b:GFP expression during early zebrafish brain development
}

\author{
Nathalie Agudelo-Dueñas ${ }^{1,2}$, Manu Forero-Shelton ${ }^{1}$, Irina V. Zhdanova ${ }^{3}$ and Veronica Akle ${ }^{2^{*}}$ (B)
}

\begin{abstract}
Objective: F-spondin is part of a group of evolutionarily conserved extracellular matrix proteins in vertebrates. It is highly expressed in the embryonic floor plate, and it can bind to the ECM and promote neuronal outgrowth. A characterization of F-spondin expression patterns in the adult zebrafish brain was previously reported by our group. However, given its importance during development, we aimed to obtain a detailed description of green fluorescent protein (GFP) expression driven by the spon 16 promotor, in the developing zebrafish brain of the transgenic Tg(spon1b:GFP) line, using light sheet fluorescence microscopy (LSFM).
\end{abstract}

Results: Images obtained in live embryos from 22 to $96 \mathrm{~h}$ post fertilization confirmed our earlier reports on the presence of spon 1b:GFP expressing cells in the telencephalon and diencephalon (olfactory bulbs, habenula, optic tectum, nuclei of the medial longitudinal fasciculus), and revealed new spon 1b:GFP populations in the pituitary anlage, dorsorostral cluster, and ventro-rostral cluster. LSFM made it possible to follow the dynamics of cellular migration patterns during development.

Conclusions: spon 1b:GFP larval expression patterns starts in early development in specific neuronal structures of the developing brain associated with sensory-motor modulation. LSFM evaluation of the transgenic Tg(spon 1b:GFP) line provides an effective approach to characterize GFP expression patterns in vivo.

Keywords: F-spondin/spon1b, GFP, Light sheet fluorescence microscopy (LSFM), Zebrafish (Danio rerio), Olfactory system, Pituitary/hypophysis, Habenula

\section{Introduction}

Spondins are a family of evolutionarily well-conserved extracellular matrix proteins characterized by the presence of thrombospondin domains. Studies of F-spondin have shown that this protein enhances neurite outgrowth, promotes nerve precursor differentiation [1] and acts as an adhesion and axon guidance molecule [2].

In zebrafish, spon $1 b$ is expressed in the forebrain, midbrain and hindbrain regions [3]. In our previous work [4] using the transgenic $T g($ spon $1 b: G F P)$ line, we reported F-spondin expression in the brain and eye regions as early

\footnotetext{
*Correspondence: v.akle@uniandes.edu.co

${ }^{2}$ Neuroscience and Circadian Rhythms Laboratory, School of Medicine,

Universidad de los Andes, Bogotá, Colombia

Full list of author information is available at the end of the article
}

as $18 \mathrm{~h}$ post-fertilization (hpf); in particular, in the notochord, floorplate, and flexural organ, in neurons extending long neuronal tracks in the CNS, and in peripheral tissues with active patterning or proliferation throughout development. A general description of spon1b:GFP expression patterns in the transgenic $T g(\operatorname{spon} 1 b: G F P)$ line was done both in zebrafish embryos and adults [4]. A detailed characterization of the GFP expression driven by the spon $1 b$ promotor in zebrafish embryos would further contribute to our understanding of the roles this protein plays during early vertebrate development.

Light sheet fluorescence microscopy (LSFM) allows imaging individual embryos at high resolution in three dimensions over time due to reduced phototoxicity. We can resolve individual cells of single individuals over periods of $24 \mathrm{~h}$ using LSFM; thus, by monitoring fluorescence

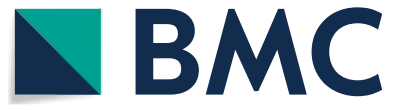

(c) The Author(s) 2020. This article is licensed under a Creative Commons Attribution 4.0 International License, which permits use, sharing, adaptation, distribution and reproduction in any medium or format, as long as you give appropriate credit to the original author(s) and the source, provide a link to the Creative Commons licence, and indicate if changes were made. The images or other third party material in this article are included in the article's Creative Commons licence, unless indicated otherwise in a credit line to the material. If material is not included in the article's Creative Commons licence and your intended use is not permitted by statutory regulation or exceeds the permitted use, you will need to obtain permission directly from the copyright holder. To view a copy of this licence, visit http://creativeco mmons.org/licenses/by/4.0/. The Creative Commons Public Domain Dedication waiver (http://creativecommons.org/publicdomain/ zero/1.0/) applies to the data made available in this article, unless otherwise stated in a credit line to the data. 
we were able to determine the initial expression and the dynamics of spon $1 b$ :GFP positive cells within each brain structure. We tracked GFP positive cell populations starting at $22 \mathrm{hpf}$, up until 4 days post-fertilization (dpf), and observed that GFP is initially expressed in specific clusters of cells in the dorsal and ventral portions of the developing telencephalon and diencephalon.

\section{Main text}

\section{Results and discussion}

\section{spon 1b:GFP expressing cell populations between 22 and 96 hpf}

Cell populations expressing spon1b:GFP were monitored in the developing zebrafish brain of the transgenic $\mathrm{Tg}$ (spon 1b:GFP) line starting at $22 \mathrm{hpf}$ using LSFM. Between 22 and $24 \mathrm{hpf}$, spon 1b:GFP expression is mainly observed in telencephalic and diencephalic regions, in four distinct populations identified here by roman numerals: I, II, III and IV (Fig. 1). Population I is the first identifiable cluster, surrounding the ventricle in a horseshoe pattern at the dorsal telencephalon (Fig. 1a).

From 25 to $36 \mathrm{hpf}$, new spon1b:GFP positive cells appear and increase the number of axonal projections among themselves (Fig. 1e). Their axons also project ventrally, toward the telencephalic midline, ending there or crossing the midline, while forming a commissure (Fig. 1e, f). Consistent with earlier neuroanatomical classifications, we identified cell population I as part of the telencephalic dorso-rostral cluster [5-7]. We suggest that these cells are part of the developing olfactory complex, consistent with the high expression in the olfactory bulbs of adults [4], and that some of the spon $1 b$ :GFP positive cells extend their axons contralaterally though the anterior commissure, as previously reported in zebrafish [7-9], and in rodents [10]. This observation was also supported by spon 1b:GFP expression by cell clusters in the telencephalon at later developmental stages (48 hpf), which anatomically correspond to the olfactory epithelium and olfactory bulbs [11].

Cells in populations II, III and IV are in the same dorso-ventral plane, caudal with respect to population I (Fig. 1b). GFP positive cells corresponding to population II are within the developing hypophysis or pituitary anlage [12], surrounded by GFP negative cells, as confirmed by the overlay of transmitted and fluorescence light images (Fig. 1b, c). Population III is composed of bilateral symmetrically located cell clusters (Fig. 1b). These cells are distributed in the neuroepithelium, showing extensions toward the midline (Fig. 1d), and caudally projecting axons (data not shown). The number of cells in population III remains similar from 24 to $48 \mathrm{hpf} \mathrm{(8-10}$ cells). Following the previous anatomical classification [5-7], we identified population III as the diencephalic ventro-rostral cluster. About five large cells $(\sim 10 \mu \mathrm{m}$ in diameter) constitute population IV (Fig. 1b), which is located at the most rostral tip of the forebrain in a region similar to the one reported for the subcommissural organ [3]. These cells do not show significant changes up to 48 hpf. Further examination until 96 hpf confirms our previous studies, in which we did not detect spon $1 b$ in the developing subcommissural organ [4], because the area below the posterior commissure appears GFP negative. It is possible that the previous accounts of subcommissural organ by Higashijima et al. [3] were related to population IV described therein.

Starting at $28 \mathrm{hpf}$, two new spon1b:GFP populations appear in the dorsal diencephalon, named $\mathrm{V}$ and VI (Fig. 1g). Cells in V are larger than those in population VI, and are clearly separate from each other (Fig. 1g). Population VI appears around $31 \mathrm{hpf}$ as two densely packed symmetric bilateral clusters (Fig. 1g). These two populations correspond to early expression in the habenula (Hb), consistent with other markers of habenular complex development with onset at $~ 32 \mathrm{hpf}$ [13].

By 48 hpf, strong spon 1b:GFP fluorescence expression appears in single cells of the optic tectum, and in individual motor neurons and projections of the nuclei of the medial longitudinal fasciculus (Fig. 1a). Between 72 and $96 \mathrm{hpf}$, the number of cells in the optic tectum increases, and different cell types are observed, which exhibit greater arborization, with axons projecting toward the tectal neuropil layers (Fig. 2b, c). This characteristic laminar structure of the optic tectum highlighted by spon $1 b$ :GFP positive cells and projections was well established at 96 hpf. Cells belonging to the flexural organ, first seen at $30 \mathrm{hpf}$, increase their fluorescence levels of spon1b:GFP to very high levels after $48 \mathrm{hpf}$ (Fig. 2a).

At $96 \mathrm{hpf}$, there was also an increased innervation of the cerebellum and hindbrain with GFP positive projections, although no spon1b:GFP expressing neurons were detected in this area (Fig. 2f). It is possible that these axons constitute part of the visual circuitry, as previous studies describe connections between the tectum and nMLF [14] and the hindbrain [15] in zebrafish. In the hindbrain, spon1b:GFP positive neurons are located in rhombomeres 3 to 6 (r3-6) (Fig. $2 \mathrm{~d}$ ), as estimated by the position relative to the otocyst [16].

\section{spon 1b:GFP expression in the habenular complex}

The difference in cell size between populations $\mathrm{V}$ and VI continues throughout development. These two populations remain separated through development, and are presumed to be ventral ( $\mathrm{vHb}$ ) and dorsomedial inferior habenula (dmHbi) subnuclei, respectively (Fig. 3). The dmHbi is part of the dorsal habenula $(\mathrm{dHb})$. Between 48 and $72 \mathrm{hpf}$, detailed time-lapse tracking 

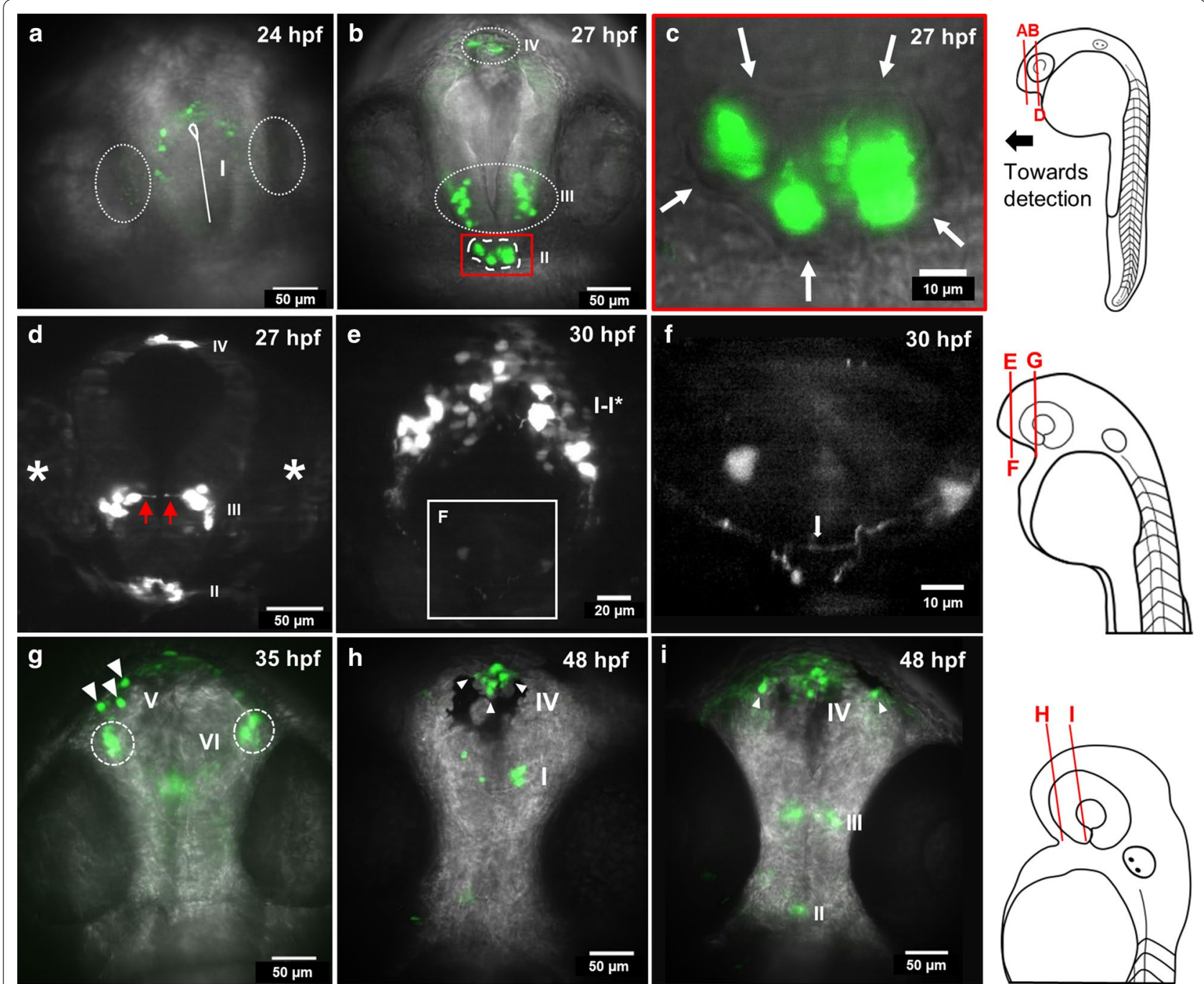

Fig. 1 spon 1b:GFP expression in cell populations from 24 to $48 \mathrm{hpf}$ in telencephalic and diencephalic regions. a Maximum intensity projection (MIP) of a $10 \mu \mathrm{m}$ optical slice of GFP fluorescence (green) overlaid with a transmitted light image (gray) for anatomical reference. This MIP at the dorsal telencephalon shows population $\mathbf{i}$. Olfactory placodes are circled for anatomical reference. Telencephalic ventricle is shown with a continuous white line. b MIP obtained from a $30 \mu \mathrm{m}$ thick slice at the developing dorsal and ventral telencephalon and diencephalon, showing populations II, III and IV. Population II corresponds to the pituitary anlage (dashed line), identified adjacent to the ventral diencephalon using transmitted light images as anatomical reference. c Detail of the pituitary anlage enclosed in red in (b). Arrows outline the border of the pituitary anlage. $\mathbf{d}$ Cells in population III show a characteristic morphology along the neuroepithelium. The MIP of a $12 \mu \mathrm{m}$ thick slice of cells in population III of a different individual shows prolongations along the developing neuroepithelium at $27 \mathrm{hpf}$ (red arrows), but at the same approximate location as (b). White asterisks indicate eye position. e MIP obtained from a $60 \mu \mathrm{m}$ slice showing the tips of axonal processes in the midline and commissure at the telencephalon from populations I-I*. f Detail of axonal processes and commissure (white arrow) enclosed in (e). $\mathbf{g}$ MIP obtained from a $75 \mu \mathrm{m}$ slice at the dorsal diencephalon and tectum showing individual cells in newly identified population V (white arrowheads), and two bilateral clusters as VI (dashed circles). h MIP obtained from a 50 um slice showing population I and IV (white arrowheads). i MIP obtained from a 90 um slice showing populations II-IV. White arrowheads show cells from the olfactory system. Images from $\mathbf{a}-\mathbf{i}$ are frontal views. Schematic drawings of zebrafish embryos at the right show the approximate position of planes in $\mathbf{a}-\mathbf{i}$

of populations $\mathrm{V}$ and VI in the same embryo revealed that these two subnuclei changed their relative position, with a close starting position and a final distance between the centers of $\sim 14 \mu \mathrm{m}$. spon 1 b:GFP expressing cells in the dmHbi subnuclei progressively change from a long and extended string-like nucleus, to become a dense round cluster of cells (Fig. 3a, f). During the $24 \mathrm{~h}$ tracking, cells located at the anterior end of the dmHbi subnuclei showed the largest displacement during the observation period. However, all cells from dmHbi migrated greater distances than the cells from $\mathrm{vHb}$ during the time observed $(\mathrm{P}<0.05)$ (Fig. $2 \mathrm{~h}$, Additional 

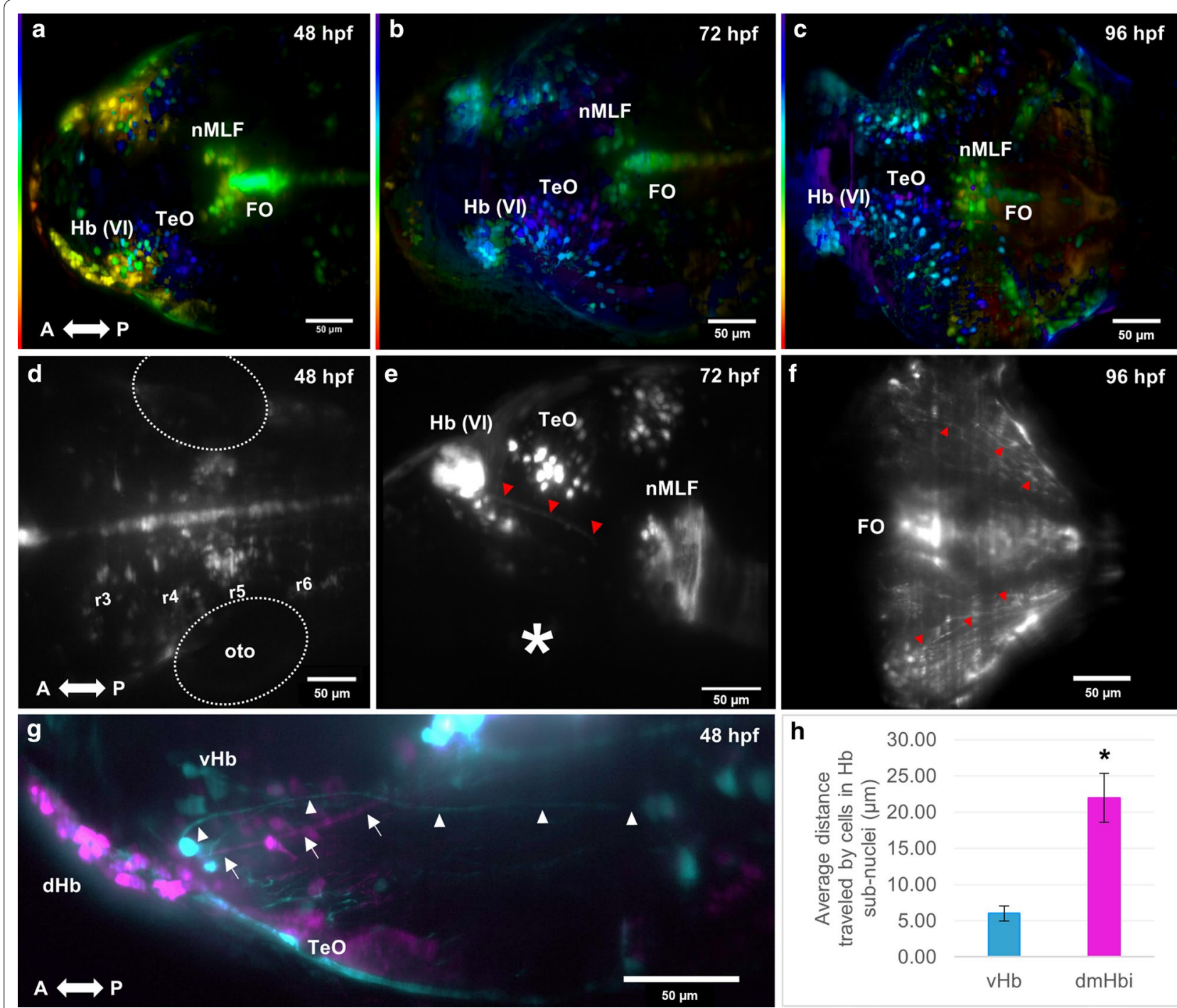

Fig. 2 spon 1b:GFP expression in cell populations from 48 to $96 \mathrm{hpf}$ in telencephalic, diencephalic and hindbrain regions. Abbreviations: $\mathrm{Hb}$, Habenula, dHb, dorsal habenula, TeO, Optic tectum, nMLF, Nuclei of the Medial Longitudinal Fasciculus, FO, Flexural Organ, a, Anterior, P, Posterior. a MIP color coded for a depth of $250 \mu \mathrm{m}$ at $48 \mathrm{hpf}$. Cells in blue are part of the TeO. Cells in yellow are part of the developing $\mathrm{Hb}$ complex. Gamma was adjusted to a value of 0.75. b MIP color coded for a depth of $200 \mu \mathrm{m}$ at $72 \mathrm{hpf}$. Cells in dark blue are part of the TeO. Cells in light blue are part of the developing $\mathrm{Hb}$ complex. Gamma was adjusted to a value of 0.75. c MIP color coded for a depth of $250 \mu \mathrm{m}$ at $96 \mathrm{hpf}$. Gamma was adjusted to a value of 0.75. d MIP obtained from a $60 \mu \mathrm{m}$ slice showing spon 1b:GFP neurons in the hindbrain at 48 hpf. Rhombomeres (r3-6) are estimated by the position relative to the otocyst (oto). e MIP obtained from a $75 \mu \mathrm{m}$ slice showing the $\mathrm{Hb}$ and the fasciculus retroflexus (red arrowheads) at $72 \mathrm{hpf}$. White asterisks indicate eye position. $\mathbf{f}$ Single plane showing an increased innervation at $96 \mathrm{hpf}$ (red arrowheads). $\mathbf{g}$ Composite image of two MIPs obtained from a depth of $5 \mu \mathrm{m}$ (cyan, depicting the $\mathrm{vHb}$ ) and $20 \mu \mathrm{m}$ (magenta depicting the $\mathrm{dHb}$ ) at $48 \mathrm{hpf}$. Axons from the developing $\mathrm{dHb}$ are observed to project caudally, neighboring the nMLF (white arrows). Axons from the developing vHb project more caudally (white arrowheads), compared to axons from the $\mathrm{dHb}$. Note the axons present within the tectal region. $\mathbf{h}$ Graph showing the average distance traveled by cells in the $\mathrm{Hb}$ subnuclei. The total distance traveled is significantly different (Mann-Whitney test, $\mathrm{P}$ value 0.0061 ) between cells in the $\mathrm{dHb}$ and the $\mathrm{vHb}$ subnuclei.. $\mathbf{a}-\mathbf{d}, \mathbf{f}-\mathbf{g}$ are dorsal views. $\mathbf{e}$ is a lateral view

file 1: Video 1). Caudal and ventral to the dmHbi, the cluster of cells pertaining to the $\mathrm{vHb}$ nucleus had cells that did not migrate relative to their initial position. The cells in vHb extended axons caudally (Fig. 3g, cyan), while axon bundles from the dmHbi nuclei at
$48 \mathrm{hpf}$ projected towards the vicinity of the nMLF, i.e. more rostrally when compared to $\mathrm{vHb}$ projections at this stage (Fig. 3g, magenta). All these projections form the habenula form the fasciculus retroflexus. At $96 \mathrm{hpf}$, axons from the FR became more compact, with the $\mathrm{Hb}$ 

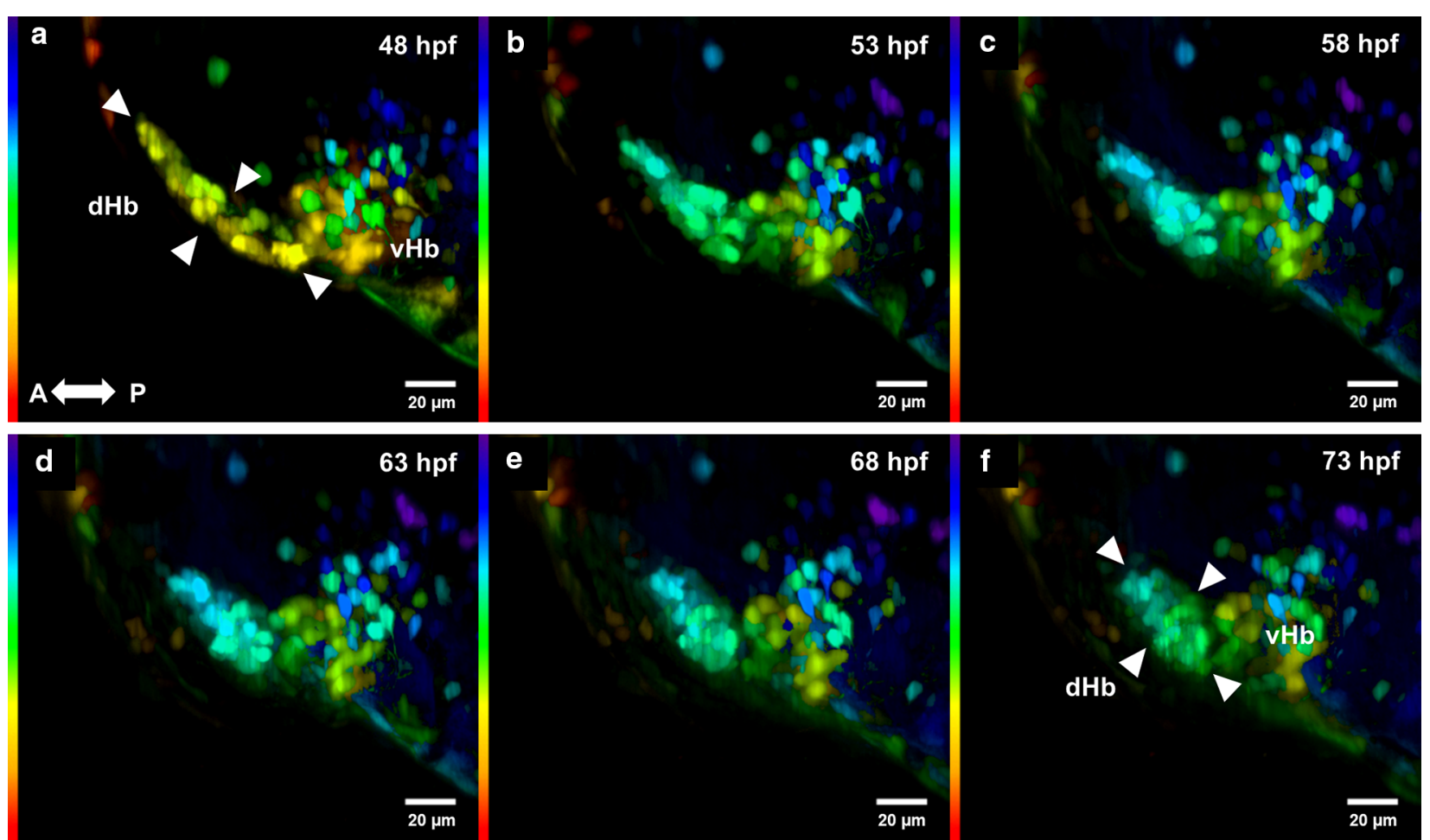

Fig. 3 Development of the habenula from 48 to $73 \mathrm{hpf}$. Development of the $\mathrm{Hb}$ complex followed through time-lapse imaging. Cells within the dorsal habenula $(\mathrm{dHb})$ aggregate progressively during development from an elongated shape to form a nucleus as indicated by the white arrowheads. The $\mathrm{dHb}$ is observed to be located more dorsally with respect to the $\mathrm{vHb}$. Images from a-f are MIP color coded for a depth of $250 \mu \mathrm{m}$, purple and blue being more dorsal, and red and orange more ventral. Original stacks were cropped and aligned using the FiJi plugin Linear Stack Alignment with SIFT [20]. Gamma was adjusted to a value of 0.75. All time points are dorsal views. A, anterior, P, posterior

nuclei being densely packed with spon $1 b: G F P$ positive cells [17] (Figs. 2, 3).

\section{Methods}

\section{Animal care and maintenance}

Adult zebrafish were housed in a controlled multi-tank recirculating water system (Aquaneering Inc.) on a $14 \mathrm{~h}$ light $-10 \mathrm{~h}$ dark cycle, at $27 \pm 1{ }^{\circ} \mathrm{C}$, according to standard protocols [18]. All protocols were approved by the Institutional Animal Care and Use Committee of Universidad de los Andes (code C.FUA_15-029).

\section{LSFM imaging}

Embryos were screened for GFP signal under a fluorescent stereoscope (Nikon AZ100M). Positive embryos were dechorionated and mounted into fluorinated ethylene propylene tubes in $0.1 \%$ agarose with tricaine $(150 \mathrm{mg} / \mathrm{L})$. Briefly, our custom-built LSFM uses a $488 \mathrm{~nm}$ laser, a $10 \times / 0.25$ objective lens (Leica) to produce a light sheet of $\sim 1.5 \mu \mathrm{m}$. A $40 \times / 0.8 \mathrm{~W}$ water objective lens (Nikon) with a bandpass filter HQ525/50M (Chroma) and a Neo camera (ANDOR) make the detection path. Temperature and aeration were maintained in the specimen chamber with a recirculating water bath. Stacks were taken at $200 \mathrm{~ms}$ exposure (power on sample 1.8-2.0 mW), every $1.0 \mu \mathrm{m}$.

\section{Image processing}

Image processing was performed in FiJi ImageJ [19]. Brightness and contrast were adjusted for better visibility. Transmitted and fluorescence images were overlaid for anatomical context. A color coded MIP Fiji macro developed by Beretta et al. [13] was applied to code depth with color. Stacks were aligned with the FiJi plugin Linear Stack Alignment with SIFT [20]. Aligned MIPs were exported to bitplane Imaris 8.2.0 for single cell tracking. Cells were modelled as $6 \mu \mathrm{m}$ spheres and tracked manually. 3D reconstructions were done in Imaris to measure the distance between $\mathrm{Hb}$ subnuclei. Schematic drawings of embryos were made using Inkscape.

\section{Data analysis}

Statistical analyses to compare dynamics of $\mathrm{vHb}$ and $\mathrm{dHb}$ cells were performed in Graphpad Prism 7. The MannWhitney $U$ test was applied to assay differences between the two Hb subnuclei. 


\section{Limitations}

- GFP detection requires expression, maturation and accumulation of the protein in cells, so the times reported here are delayed with respect to expression. Results with anti-spon $1 b$ fluorescence in situ hybridization (FISH) might be slightly different, especially in regions with abundance of projections and no cell somas.

- spon1b mRNA expression using in situ hybridization (ISH) was not used, since the correspondence of spon $1 b$ expression using ISH and the transgenic line was previously confirmed [4].

- The function of F-spondin remains elusive, and additional experiments that block the protein and test expression in individual cells should be considered.

\section{Supplementary information}

Supplementary information accompanies this paper at https://doi. org/10.1186/s13104-019-4876-x.

Additional file 1: Video 1. Displacement of cells in the habenula subnuclei from 48 to $75.5 \mathrm{hpf}$. Time-lapse imaging allowed tracking individual cells from the dorsal habenula $(\mathrm{dHb})$ and ventral habenula $(\mathrm{vHb})$ subnuclei, showing that $\mathrm{dHb}$ cells exhibit a greater displacement (measured as displacement squared) when compared to the $\mathrm{vHb}$, as represented by the displacement color code. The video is a progression of MIPs from a depth of $250 \mu \mathrm{m}$. Initial time point corresponds to $48 \mathrm{hpf}$. Original stacks were cropped and aligned using the FiJi plugin Linear Stack Alignment with SIFT (Lowe, 2004). Gamma was adjusted to a value of 0.75 . Anterior is left. Dorsal views.

\section{Abbreviations}

$\mathrm{dHb}$ : dorsal habenula; dmHbi: dorsomedial inferior habenula; dpf: days post-fertilization; GFP: green fluorescent protein; Hb: habenula; hpf: hours post-fertilization; LDFM: light sheet fluorescence microscopy.

\section{Acknowledgements}

We thank Carlo Beretta for kindly providing us the MIP color code to visualize 3D data from the LSFM. We also thank Yeferzon Ardila for animal care, and Jorge Madrid and Ángela Narváez for technical assistance with the LSFM.

\section{Authors' contributions}

VA, MFS and NAD conceived and designed the work. NAD acquired and analyzed the LSFM data. VA and IZ designed the transgenic line. All authors interpreted the data. NAD wrote the manuscript with significant contributions from all authors. All authors read and approved the final manuscript.

\section{Funding}

This work was funded by the Colombian Administrative Department of Science, Technology and Innovation (COLCIENCIAS) and the School of Medicine and the Vice-presidency of Research of Universidad de los Andes, under the Young Researchers and Innovators Fellowship 2016 (No. 761) to NAD. MFS received funding from the Department of Physics of Universidad de los Andes for parts and supplies. The funding agencies did not play any role in the design, data collections, analysis or writing of this manuscript.

\section{Availability of data and materials}

Raw datasets from exemplary developmental stages (24, 48, 72, and 96 hpf) were made publicly available in the following repository:
https://figshare.com/projects/Patterns_of_spon1b_GFP_expression_durin g_early_zebrafish_development/72812

\section{Ethics approval and consent to participate}

All protocols were approved by the Institutional Animal Care and Use Committee of Universidad de los Andes (code C.FUA_15-029).

\section{Consent for publication}

Not applicable.

\section{Competing interests}

The authors declare that they have no competing interests.

\section{Author details}

${ }^{1}$ Biophysics Group, Department of Physics, Universidad de los Andes, Bogotá, Colombia. ${ }^{2}$ Neuroscience and Circadian Rhythms Laboratory, School of Medicine, Universidad de los Andes, Bogotá, Colombia. ${ }^{3}$ BioChron LLC, Boston, MA, USA.

Received: 23 October 2019 Accepted: 24 December 2019

Published online: 07 January 2020

References

1. Schubert D, Klar A, Park M, Dargusch R, Fischer WH. F-spondin promotes nerve precursor differentiation. J Neurochem. 2006;96(2):444-53.

2. Zisman S, Marom K, Avraham O, Rinsky-Halivni L, Gai U, Kligun G, et al. Proteolysis and membrane capture of F-spondin generates combinatorial guidance cues from a single molecule. J Cell Biol. 2007;178(7):1237-49.

3. Higashijima S, Nose A, Eguchi G, Hotta Y, Okamoto H. Mindin/F-spondin family: novel ECM proteins expressed in the zebrafish embryonic axis. Dev Biol. 1997:192(2):211-27.

4. Akle V, Guelin E, Yu L, Brassard-Giordano H, Slack BE, Zhdanova IV. F-Spondin/spon $1 b$ expression patterns in developing and adult zebrafish. PLoS ONE. 2012;7(6):e37593.

5. Ross LS, Parrett T, Easter SS. Axonogenesis and morphogenesis in the embryonic zebrafish brain. Neurosci. 1992;12(2):467-82.

6. Bak M, Fraser SE. Axon fasciculation and differences in midline kinetics between pioneer and follower axons within commissural fascicles. Development. 2003;130(20):4999-5008.

7. Gaudin A, Hofmeister W, Key B. Chemoattractant axon guidance cues regulate de novo axon trajectories in the embryonic forebrain of zebrafish. Dev Biol. 2012;367(2):126-39.

8. Whitlock KE, Westerfield M. The olfactory placodes of the zebrafish form by convergence of cellular fields at the edge of the neural plate. Development. 2000;127(17):3645-53.

9. Barresi MJF, Hutson LD, Chien C-B, Karlstrom RO. Hedgehog regulated Slit expression determines commissure and glial cell position in the zebrafish forebrain. Development. 2005;132(16):3643-56.

10. Jouandet ML, Hartenstein V. Basal telencephalic origins of the anterior commissure of the rat. Exp Brain Res. 1983;50(2-3):183-92.

11. Yoshihara Y. Molecular genetic dissection of the zebrafish olfactory system. Chemosensory systems in mammals, fishes, and insects. Springer: Berlin, Heidelberg; 2008. p. 1-19. https://doi.org/10.1007/400_2008_1.

12. Liu N-A, Ren M, Song J, Ríos Y, Wawrowsky K, Ben-Shlomo A, et al. In vivo time-lapse imaging delineates the zebrafish pituitary proopiomelanocortin lineage boundary regulated by FGF3 signal. Dev Biol. 2008;319(2):192-200

13. Beretta CA, Dross N, Guglielmi L, Bankhead P, Soulika M, Gutierrez-Triana $\mathrm{JA}$, et al. Early commissural diencephalic neurons control habenular axon extension and targeting. Curr Biol. 2017;27(2):270-8.

14. Gahtan E, Tanger P, Baier H. Visual prey capture in larval zebrafish is controlled by identified reticulospinal neurons downstream of the tectum. J Neurosci. 2005;25(40):9294-303.

15. Robles E, Smith SJ, Baier H. Characterization of genetically targeted neuron types in the zebrafish optic tectum. Front Neural Circuits. 2011;5:1. https://doi.org/10.3389/fncir.2011.00001/full.

16. Higashijima S, Hotta Y, Okamoto H. Visualization of cranial motor neurons in live transgenic zebrafish expressing green fluorescent protein under 
the control of the islet-1 promoter/enhancer. J Neurosci Off J Soc Neurosci. 2000;20(1):206-18.

17. Posey KL, Hankenson K, Veerisetty AC, Bornstein P, Lawler J, Hecht JT. Skeletal abnormalities in mice lacking extracellular matrix proteins, thrombospondin-1, thrombospondin-3, thrombospondin-5, and type IX collagen. Am J Pathol. 2008;172(6):1664-74.

18. Westerfield M. The zebrafish book: a guide for the laboratory use of zebrafish (Danio rerio). 4th ed. Eugene: University of Oregon Press; 2000.

19. Schindelin J, Arganda-Carreras I, Frise E, Kaynig V, Longair M, Pietzsch T, et al. Fiji: an open-source platform for biological-image analysis. Nat Methods. 2012;9(7):676-82.
20. Lowe DG. Distinctive image features from scale-invariant keypoints. Int J Comput Vis. 2004;60(2):91-110.

\section{Publisher's Note}

Springer Nature remains neutral with regard to jurisdictional claims in published maps and institutional affiliations.
Ready to submit your research? Choose BMC and benefit from:

- fast, convenient online submission

- thorough peer review by experienced researchers in your field

- rapid publication on acceptance

- support for research data, including large and complex data types

- gold Open Access which fosters wider collaboration and increased citations

- maximum visibility for your research: over $100 \mathrm{M}$ website views per year

At BMC, research is always in progress.

Learn more biomedcentral.com/submissions 